\title{
Simulating the effect of anthropogenic vegetation land cover on heatwave temperatures over central France
}

\author{
M. Stéfanon ${ }^{1, *}$, S. Schindler ${ }^{2}$, P. Drobinski ${ }^{2}$, N. de Noblet-Ducoudré ${ }^{3}$, F. D'Andrea ${ }^{2}$ \\ ${ }^{1}$ Laboratoire d'Écologie Systématique et Évolution (ESE), CNRS/UPSUD/AgroParisTech, Orsay, France \\ ${ }^{2}$ Laboratoire de Météorologie Dynamique (LMD) - Institut Pierre Simon Laplace, CNRS/Ecole Polytechnique/ENS/UPMC, \\ Paris, France \\ ${ }^{3}$ Laboratoire des Sciences du Climat et de l'Environnement (LSCE) - Institut Pierre Simon Laplace, CEA/CNRS/UVSQ, \\ Gif sur Yvette, France
}

\begin{abstract}
Events similar to the 2003 heatwaves in France are likely to become more frequent, more intense and longer by the end of the 21st century. Policies for climate mitigation focus on carbon sequestration techniques while land cover change (LCC) may be a better short-term alternative at regional level. However, LCC impact studies conducted so far have often given contradictory results at mid-latitudes for summer temperature. Using a regional climate model, the impact of an afforestation scenario is evaluated for the years 2002 and 2003, and compared to an agricultural scenario. The favorable meteorological conditions in spring 2003 promote the development of agricultural vegetation compared to (1) conditions in 2002 and (2) tree phenology in the forested scenario. This dampens the extreme values of temperature from April to the end of June 2003 (up to $3^{\circ} \mathrm{C}$ during the June heatwave). From early July to October, drought conditions cause crop failure, while forests are not affected by the lack of soil moisture owing to a deeper root system. Evapotranspiration is therefore smaller in the agricultural scenario, thus amplifying the July-August extreme temperatures. However this cooling capacity of trees in the afforestation scenario is limited during the August heatwave because the high temperatures reach a critical level above which the stomata close and transpiration is inhibited. Our experimental set-up highlights the role of climate-vegetation interactions during extreme events and demonstrates how choices of vegetation cover (e.g. trees versus crops) may substantially modify the summer temperatures in mid-latitude regions.
\end{abstract}

KEY WORDS: Heatwave · Vegetation · Land cover change $\cdot$ Phenology $\cdot$ Regional climate model Afforestation Resale or republication not permitted without written consent of the publisher

\section{INTRODUCTION}

The distribution of vegetation around the globe follows diverse environmental constraints, including climatic, geological, biogeochemical and anthropogenic factors. Human influence alters vegetation distribution through $\mathrm{CO}_{2}$ emissions and its consequences on climate, as well as through land use changes. While climate change could cause shifts in vegetation distribution during the 21st century (Bakkenes et al. 2002, Cox et al. 2004), deforestation for the extension of agricultural surfaces has shaped European and Mediterranen landscapes since the Roman era. During the last $50 \mathrm{yr}$, land cover change (LCC) slowed down in Europe and agricultural surfaces even diminished in some regions as indicated 
by Food and Agriculture Organization (FAO) statistics (Pielke et al. 2011).

LCC also feeds back on the climate itself, this impact being difficult to assess in observational systems because of its spatial heterogeneity and because of the difficulty in isolating the effects of LCC from other effects. Changes in vegetation distribution affect a multitude of parameters including albedo, surface roughness, evapotranspiration and the water cycle in general (Heck et al. 2001). For example, the partitioning of turbulent heat fluxes plays a role in the dynamics of the planetary boundary layer height and determines the moist energy available, hence influencing the development of convective clouds and precipitation. The impacts of LCC can change depending on the initial vegetation distribution (change from grass to trees, or vice versa) and the surrounding environment (homogenization or structural diversification of the landscape). While several authors estimate the global influence of LCC in comparison to greenhouse gas forcing to be weak (Forster et al. 2007, Wramneby et al. 2010, Gálos et al. 2011), they also acknowledge that the climatic effect is not negligible on the regional weather (Findell et al. 2007, Pitman et al. 2009, Gálos et al. 2011) and affirm the need for further research (Pielke et al. 2011).

While the Intergovernmental Panel for Climate Change (IPCC) 4th Assessment Report (AR4) did not take into account LCC, in AR5 each representative concentration pathway (RCP) has its own LCC scenario: the least conservative modifies $9 \%$ of the total surface in the Mediterranean area. However, modellers have also imagined several more drastic deforestation (afforestation) scenarios in order to shed light on the physical processes at play in the LCC-climate interactions. Changes in forest cover have an impact first of all on the water balance in tropical latitudes, while it is the energy balance via the surface albedo that reacts most sensitively at high latitudes (Jackson et al. 2008, Davin \& de Noblet-Ducoudré 2010). Over tropical areas (Amazonia), typical deforestation scenarios involve the tropical rainforest being replaced by pasture. Surface warming results from a lower evaporative cooling than in the forest, slightly dampened by higher pasture albedo (Lean \& Rowntree 1997, von Randow et al. 2004). At boreal latitudes, forest expansion tends to warm the surface through a snow masking effect, snow-covered forest albedo being by far inferior to snow-covered grassland albedo (Chalita \& Le Treut 1994, Meissner et al. 2003). At mid-latitudes, both mechanisms are moderately at work and competing against each other so that the impact of LCC on summer temperature can be positive or negative (Bonan et al. 2008).

In the Mediterranean, these studies tend to agree that LCC has a significant impact on regional climate through changes in evapotranspiration. The results of these modeling studies are somewhat contradictory, and appear to be strongly dependent on the experimental setup, specificities of the land surface model and vegetation parameterization. For example, according to Gaertner et al. (2001), deforestation causes a decrease in evapotranspiration, while the same effect was observed by Anav et al. (2010a) and Zampieri \& Lionello (2011) for the opposite land cover change: afforestation reduced evapotranspiration and increased sensible heat flux during summer. Heck et al. (2001) suggested that an afforested Mediterranean could result in a moister and cooler climate from April to mid-July, until evapotranspiration is inhibited because the soil moisture decreases to a critical value.

The heatwaves of June and August 2003 in Western Europe are the result of a combination of a persistent synoptic circulation pattern amplified by local soil moisture deficit and vegetation feedbacks (Schär et al. 2004, Fischer et al. 2007, Stéfanon et al. 2012b). A warm sea surface temperature in the Atlantic Ocean and the Mediterranean was also related to the 2003 heatwaves. Warmer SSTs are associated with a strengthening of the persistent anticyclonic situation over Europe (e.g. Cassou et al. 2005, Della-Marta et al. 2007, Feudale \& Shukla 2010). Although such heatwaves remain exceptional, several studies have shown that, associated with an increase in temperature mean and variability in the context of global warming, these phenomena have become not only more frequent but also longer and more intense during the 20th century (Easterling et al. 2000, Klein Tank et al. 2005, Della-Marta et al. 2007) - a trend that could continue in the 21st century (Beniston 2004, Ballester et al. 2010).

So far, most of the research on land-climate interactions has focused on the feedback between climate and soil moisture or on the impacts of climatic variability on species distribution and phenology. Few articles have attempted to evaluate the feedback mechanisms that vegetation can exert on meteorological fields (for a review see Pielke et al. 2011). In this study we use numerical modeling to investigate the effects of LCC on climate-vegetation interactions during the 2003 summer heatwaves. We test the sensitivity of climate to a hypothetical absence of human activities, replacing all kind of crops with forest and natural grass. This scenario, which we call the 'potential vegetation' scenario, clearly does not rep- 
resent a realistic land cover perturbation; instead, it aims to compare the maximum effects of human action on a specific climate extreme through LCC.

For this purpose, we use the non-hydrostatic Weather and Research Forecasting (WRF) model coupled with the ORCHIDEE (ORganizing Carbon and Hydrology In Dynamic EcosystEms) landsurface model, which explicitly computes photosynthesis, vegetation carbon cycle and phenology. The domain of the simulation is shown in Fig. 1. It corresponds to an area where heatwave patterns appear recurrently (Stéfanon et al. 2012a) and soilatmosphere interactions are a key element of heatwave preconditionning (Fischer et al. 2007). Vautard et al. (2007) and Zampieri et al. (2009) highlighted that drought and heat can spread northward from Southern Europe, amplifying the heatwaves in central Europe. However, in our experiment, such a mechanism is not explicitly simulated because of the domain size but is partially represented through our boundary conditions.

\section{MODEL CONFIGURATION AND SIMULATION SET-UP}

\subsection{Model}

We use the Model of the Regional Coupled Earth system (MORCE) to represent physical, biophysical and biogeochemical interactions between atmosphere, land and ocean surfaces (Drobinski et al. 2012). The version used here was developed at IPSL (Institut Pierre Simon Laplace) and includes the WRF model and the ORCHIDEE land-surface model.

The WRF model of the National Center for Atmospheric Research (NCAR) (Skamarock et al. 2008) has already been used to investigate the effect of interactive vegetation on the amplitudes of the summer 2003 heatwaves (Stéfanon et al. 2012b).

The domain of integration covers part of continental France with a horizontal resolution of $15 \mathrm{~km}$ (see red box in Fig. 1). It has 28 sigma-levels in the vertical. Initial and lateral conditions are from the ERAInterim reanalysis of the European Centre for Medium-Range Weather Forecasts (ECMWF; Dee et al. 2011) provided every $6 \mathrm{~h}$ with a $0.75^{\circ} \times 0.75^{\circ} \mathrm{lon}-$ gitude-latitude resolution.

WRF is coupled to the land surface model ORCHIDEE, which is based on 3 different modules (Krinner et al. 2005). (1) SECHIBA (Schématisation des EChanges Hydriques à l'Interface entre la Biosphère et l'Atmosphère), describes the fast pro-

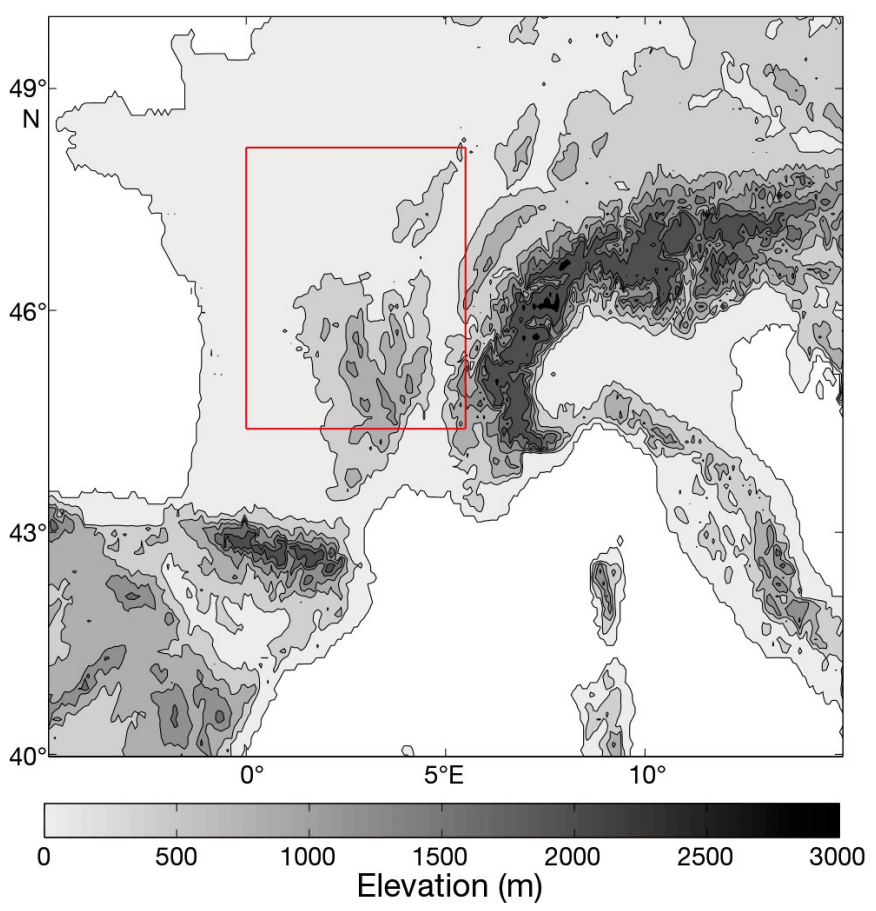

Fig. 1. Integration domain of the simulations (box) over continental France

cesses such as the soil water budget and the exchanges of energy, water and $\mathrm{CO}_{2}$ through photosynthesis between the atmosphere and the biosphere (Ducoudré et al. 1993, Viovy \& de Noblet-Ducoudré 1997). (2) The phenology and carbon dynamics of the terrestrial biosphere are simulated by the STOMATE module (Saclay Toulouse Orsay Model for the Analysis of Terrestrial Ecosystems). STOMATE essentially simulates processes such as maintenance and growth respiration, carbon allocation, litter decomposition, soil carbon dynamics, and phenology. (3) The Lund Postdam Jena (LPJ; vegetation dynamics) submodel, which simulates vegetation dynamics and is also included in ORCHIDEE, is not activated for this work. Soil hydrology follows the Choisnel model: 2 distinct layers store the water in an upper and a lower reservoir (Ducoudré et al. 1993). Soil moisture in the upper layer is the most reactive. It is determined by moisture convergence but is more complex than a bucket since its depth varies in time. If rainfall occurs, soil is filled from top to bottom, and when evapotranspiration exceeds rainfall, water is removed from the upper level where it is available.

Hydrological balance is computed for each plant functional type (PFT), and the various water reservoirs are independent horizontally. According to their root depth profile, the PFTs are able to reach either the superficial reservoir or both reservoirs to 
extract water. Vegetation in ORCHIDEE is represented by 12 PFTs, including 2 agricultural PFTs for 2 different photosynthetic pathways $\left(\mathrm{C}_{3}\right.$ and $\left.\mathrm{C}_{4}\right)$, and bare soil. Each grid cell is partitioned into the various PFTs. Surface roughness depends on tree height and leaf area index (LAI). Albedo depends on soil color and moisture, PFT type and LAI. Phenology is PFTspecific and has temperature or/and humidity based trigger values for leaf-onset and senescence. Incoming radiation is attenuated by the vegetation canopy according to the Beer-Lambert law, while there is no vertical gradient of humidity and $\mathrm{CO}_{2}$ concentration inside the canopy. Stomatal conductance $\left(G_{\mathrm{s}}\right)$ is a function that depends on photosynthesis $(A)$, atmospheric relative humidity $\left(h_{\mathrm{r}}\right)$ and $\mathrm{CO}_{2}$ concentration at the leaf surface $\left(C_{\mathrm{a}}\right)$ (Ball 1987, Collatz et al. 1991, Farquhar et al. 1980):

$$
G_{\mathrm{s}}=G_{\mathrm{s}, \text { slope }} \frac{h_{\mathrm{r}}}{C_{\mathrm{a}}} A+G_{\mathrm{s}, \text { offset }}
$$

$G_{\mathrm{s}, \mathrm{slope}}$ and $G_{\mathrm{s}, \text { offset }}$ are empirical parameters. In the absence of photosyntesis $(A=0)$, the stomatal conductance decreases to its minimum $\left(1.10^{-2} \mathrm{mmol} \mathrm{m}^{-2}\right.$ $\mathrm{s}^{-1}$ for all PFTs). $A$ is defined as:

$$
A=\Gamma_{\min }\left(V_{\mathrm{c}}\left(V_{\mathrm{cmax}}\right), V_{\mathrm{j}}\right)-R_{\mathrm{d}}
$$

where $\Gamma$ is a unitless coefficient representing the distance from the tipping point between the $\mathrm{CO}_{2}$ uptake by photosynthesis and $\mathrm{CO}_{2}$ emission by photorespiration and cellular respiration, and $R_{\mathrm{d}}$ is the mitochondiral respiration. $\Gamma$ and $R_{\mathrm{d}}$ depend on leaf internal $\mathrm{CO}_{2}$ concentration and dark respiration. $A$ also depends on plant physiological condition $\left(V_{\mathrm{c}}\right)$ and incoming solar radiation $\left(V_{\mathrm{j}}\right)$. The quantity $V_{\mathrm{c}}$ is directly proportional to the maximal carboxylation rate $V_{\text {cmax }}$. This rate is a function of 3 unitless factors between 0 and 1 , corresponding to water stress, heat stress and leaf age $\left(\varepsilon_{\text {water }}, \varepsilon_{\text {temp }}\right.$ and $\varepsilon_{\text {leaf }}$ respectively):

$$
V_{\text {cmax }}=V_{\text {cmax }, \text { opt }} \times \varepsilon_{\text {water }} \times \varepsilon_{\text {temp }} \times \varepsilon_{\text {leaf }}
$$

where $V_{\text {cmax opt }}$ is an empirical parameter. High stress is associated with low value of $\varepsilon_{\text {water, }} \varepsilon_{\text {temp }}$ and $\varepsilon_{\text {leaf }}$ while high values close to 1 indicate a low stress and a maximum $V_{\text {cmax }}$ value. When incoming solar radiation is low, i.e. when $V_{\mathrm{j}}$ is expected to be smaller than $V_{\mathrm{c}}\left(V_{\text {cmax }}\right), A$ only depends on $V_{\mathrm{j}}$ (see Eq. 2). During daytime and under sunny weather conditions, as will be investigated in this study, one expects $V_{\mathrm{j}}$ to be larger than $V_{\mathrm{c}}\left(V_{\mathrm{cmax}}\right)$, and so $A$ only depends on $V_{\mathrm{c}}\left(V_{\text {cmax }}\right)$ (see Eq. 2). The quantity $\varepsilon_{\text {water }}$ is computed through a water uptake function. It is related to the exponential structure of the root system and vertical soil moisture profile and represents the roots' ability to extract water from the soil for a given humidity. Photosynthesis limitation by temperature $\left(\varepsilon_{\text {temp }}\right)$ is modeled by a parabolic response to air temperature, with a minimum, optimum and maximum temperature value specific to each PFT. Beyond the maximum temperature, $\varepsilon_{\text {temp }}=0$ and thus $A=0$ (see Eqs. $2 \& 3$ ).

\subsection{Numerical experiments}

For the years 2002 and 2003, 2 simulations were performed, one with the current vegetation distribution (CUR simulation) and one with a potential vegetation distribution (POT simulation). No spin-up of the model was performed, but soil moisture reaches an 'equilibrium' after 4 mo (with a remaining much slower evolution that does not affect the results of the study). Indeed, winter rainfall replenishes the soil until saturation, and equilibrium is reached before the summer months.

The vegetation map was obtained from the Advanced Very High Resolution Radiometer (AVHRR) satellite observations between 1992 and 1993 (Loveland et al. 2000). In ORCHIDEE, this map was reclassified with respect to the 12 PFTs and a desert category at a $5 \mathrm{~km}$ horizontal resolution. It will be referred to as the CUR map hereafter. For the potential vegetation map (hereafter POT map), the CUR map was aggregated to a $0.5^{\circ} \times 0.5^{\circ}$ longitudelatitude resolution, and the surface fractions occupied by agricultural land uses were replaced by the dominant natural PFTs. Finally, the POT and CUR maps were interpolated and aggregated, respectively, to the simulation horizontal resolution of $15 \mathrm{~km}$. Since we compare 2 opposite scenarios of land cover (POT and CUR), the difference between the 2 simulations is large compared to the difference that an updated version of ORCHIDEE vegetation map would produce. Work is ongoing to produce an updated vegetation map.

On average over the whole domain, LCC in the POT map is $\sim 90 \%$ of the CUR map, meaning that $90 \%$ of the total surface has changed its dominant PFT. The distribution of vegetation in the 2 integrations is summarized in Fig. 2. The CUR vegetation distribution is strongly dominated by croplands (agricultural $\mathrm{C}_{3}: \mathrm{AC}_{3}$ ), present in $88 \%$ of the domain, whereas forest and mixed vegetation account for $12 \%$, respectively (Fig. 2c,d). Forests are located mainly in the southern part of the domain and on mountain slopes, which are therefore less affected by LCC, whereas in the northern part, forests are very scattered. The POT vegetation distribution presents 


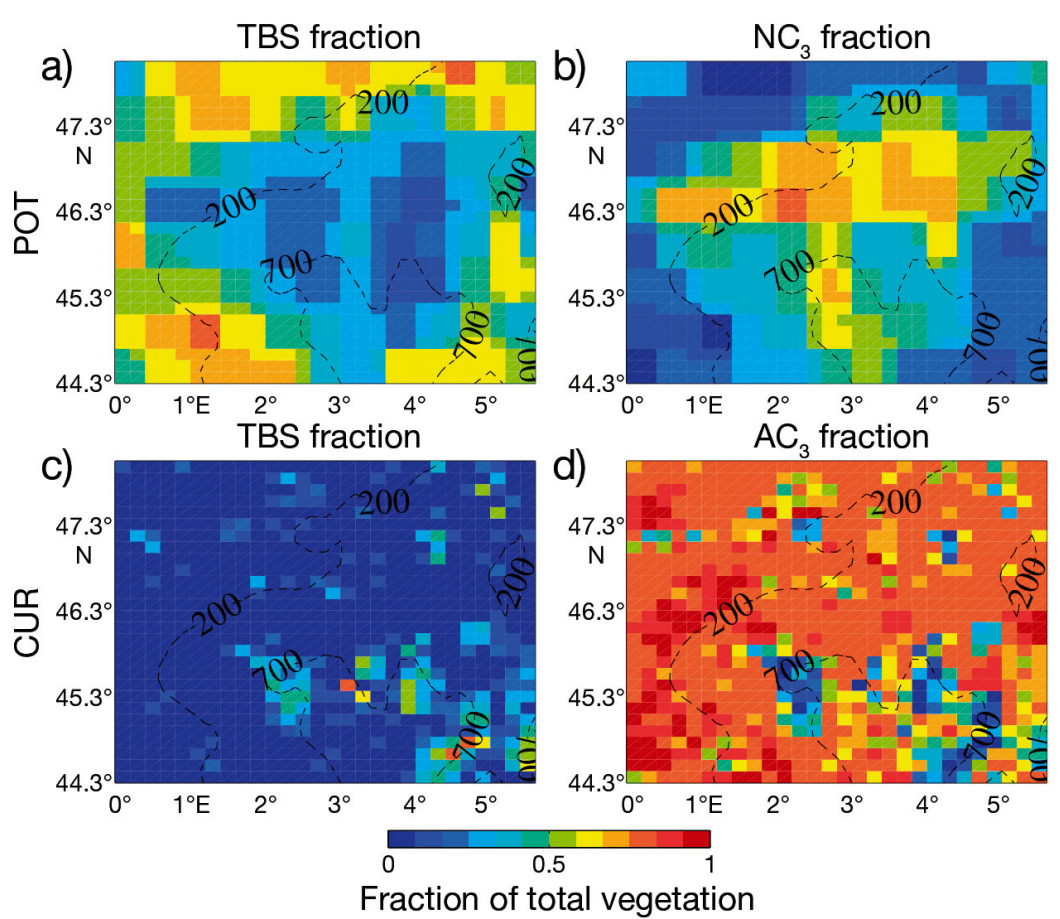

Fig. 2. Vegetation distribution per grid cell for the potential vegetation distribution (POT simulation) (upper row) and current vegetation distribution (CUR; lower row). $(\mathrm{a}, \mathrm{c})$ Temperate broadleaf summergreen trees (TBS), (b) natural $\mathrm{C}_{3}$ grass $\left(\mathrm{NC}_{3 i}\right)$ and $(\mathrm{d})$ agricultural $\mathrm{C}_{3}$ grass $\left(\mathrm{AC}_{3}\right)$. Dashed lines: elevation ( $\mathrm{m}$, a.s.l.)

a mix between forest and herbaceous vegetation (natural $\mathrm{C}_{3}: \mathrm{NC}_{3}$ ) covering 61 and $39 \%$ of the domain's surface, respectively. Forests are located on the edges, while herbaceous plants are in the center of the domain (Fig. 2a,b).

\section{RESULTS}

\subsection{Analysis of temperature anomaly}

Fig. 3 displays the horizontal pattern of the temperature difference between the POT and CUR simulations averaged over the June (Fig. 3a) and August (Fig. 3b) heatwave periods. Revegetating the land induces a positive temperature anomaly in June of $+0.42^{\circ} \mathrm{C}$ on average (in time and space), reaching $+3^{\circ} \mathrm{C}$ locally, while the anomaly in August is negative $\left(-0.20^{\circ} \mathrm{C}\right.$ on average in time and space), reaching $-1.6^{\circ} \mathrm{C}$ locally. These values are calculated at 15:00 $\mathrm{h}$ UTC, which approximately corresponds to the warmest period of the day. Considering that the June and August heatwaves displayed a temperature anomaly of about $+8^{\circ} \mathrm{C}$ with respect to the climatology (Feudale \& Shukla 2010), LCC modifies the total temperature anomaly associated with them by $\sim 5 \%$ on average and up to $37 \%$ locally. In June, the smallest temperature differences $\left(<0.5^{\circ} \mathrm{C}\right)$ are located in the southern part of the domain, while the largest differences are found in the north.

To identify the reasons that lead to these contrasted vegetation-induced surface air temperature changes between the June and August heatwaves (heating followed by cooling), we consider the surface energy budget (SEB):

$K \downarrow+I \downarrow=K \uparrow+I \uparrow+Q_{\mathrm{H}}+Q_{\mathrm{L}}+Q_{\mathrm{G}}$

where $K$ and $I$ are shortwave and longwave radiation incoming (downward arrows) and reflected back (upward arrows) at the surface, $Q_{\mathrm{H}}$ is the sensible heat flux, $Q_{\mathrm{L}}$ the latent heat flux and $Q_{\mathrm{G}}$ the ground flux.

If $Q_{\mathrm{a}}=K \downarrow+I \downarrow$ is the downward radiation at the surface and $Q_{\mathrm{t}}=Q_{\mathrm{H}}+Q_{\mathrm{L}}$ is the sum of the turbulent heat fluxes, the fraction $F=Q_{\mathrm{a}} / Q_{\mathrm{t}}$ is a relevant indicator to quantify the fraction of incoming energy that contributes to the heating of the atmosphere and to evaporation (Boisier et al. 2012, de Noblet-Ducoudré et al. 2012). In our case, about $40 \%$ of the incoming energy is turned into turbulent heat fluxes in both POT and CUR simulations, while the remaining $60 \%$ is reflected back to space or used to warm up the land surface. The difference of $F$ between the 2 simulations $(\delta F)$ during the June and August heatwaves can be analysed in terms of different physical processes. We can write $\delta F$ as follows:

$$
\delta F=\frac{\partial F}{\partial Q_{\mathrm{a}}} \delta Q_{\mathrm{a}}+\frac{\partial F}{\partial Q_{\mathrm{t}}} \delta Q_{\mathrm{t}}=\frac{1}{Q_{\mathrm{t}}} \delta Q_{\mathrm{a}}-\frac{Q_{\mathrm{a}}}{Q_{\mathrm{t}}^{2}} \delta Q_{\mathrm{t}}
$$

Let us express $Q_{\mathrm{t}}$ as a function of $Q_{\mathrm{H}}$ and the Bowen ratio, $\beta=Q_{\mathrm{H}} / Q_{\mathrm{L}}$, i.e. $Q_{\mathrm{t}}=(1+\beta) Q_{\mathrm{L}}$. The quantity $\delta Q_{\mathrm{t}}$ can be written as:

$$
\delta Q_{\mathrm{t}}=(1+\beta) \delta Q_{\mathrm{L}}+\delta \beta Q_{\mathrm{L}} t
$$

and Eq. (5) thus becomes:

$$
\delta F=\underbrace{\frac{1}{(1+\beta) Q_{\mathrm{L}}} \delta Q_{\mathrm{a}}}_{{ }_{\delta} F_{\mathrm{RAD}}}-\underbrace{\frac{Q_{\mathrm{a}}}{(1+\beta) Q_{\mathrm{L}}^{2}} \delta Q_{\mathrm{L}}}_{{ }_{\delta} F_{\mathrm{GRAD}}}-\underbrace{\frac{Q_{\mathrm{a}}}{(1+\beta)^{2} Q_{\mathrm{L}}} \delta \beta}_{{ }^{{ }_{F} \mathrm{SUR}}}
$$

The quantity $\delta F_{\mathrm{RAD}}$ represents the contribution of cloud cover change between POT and CUR simulations to atmospheric heating. The quantity $\delta F_{\text {GRAD }}$ represents the modification of the thermal stratification of the atmosphere produced by a change in surface roughness as well as by possible atmospheric 

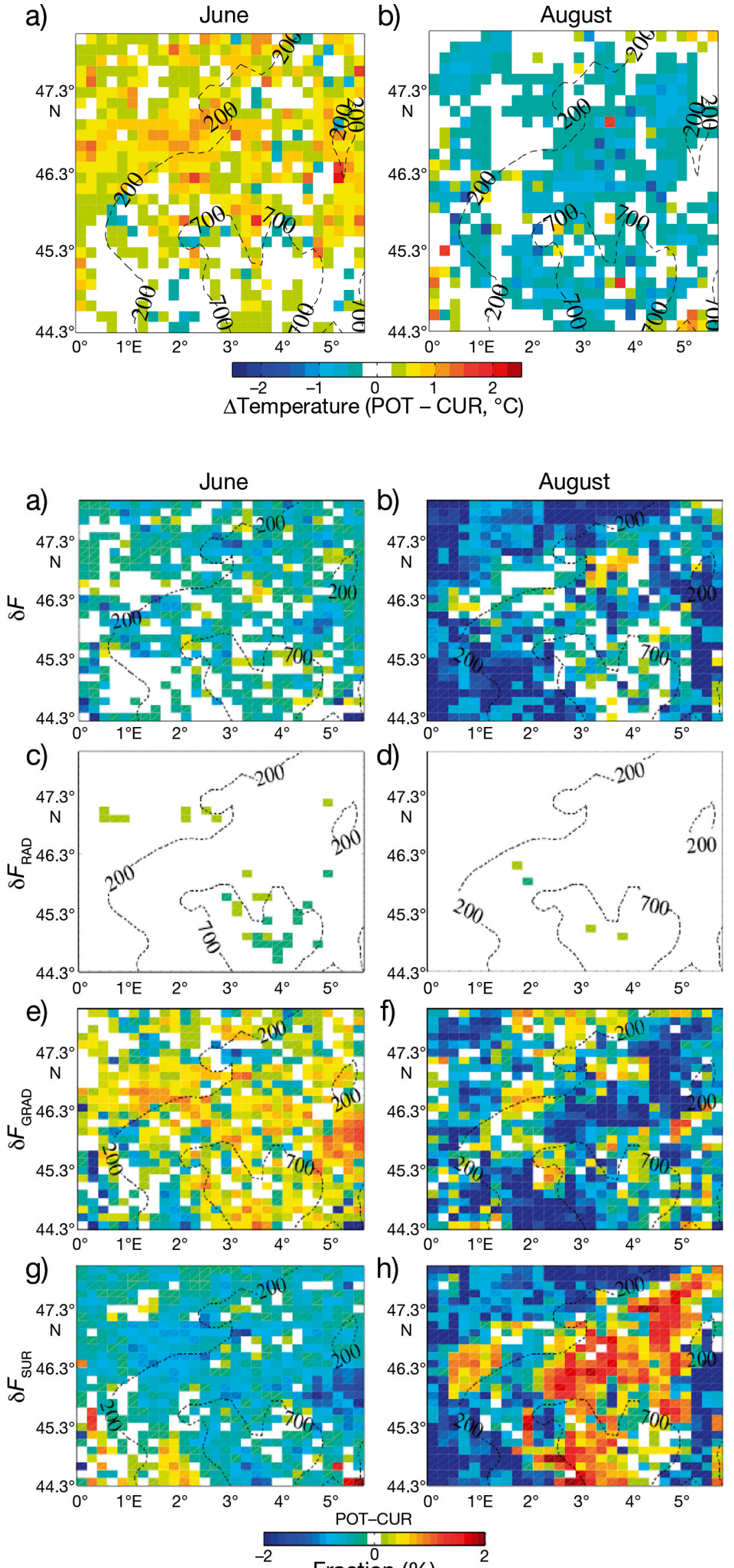

Fig. 3. Difference in surface air temperatures (at $2 \mathrm{~m}$ above ground) between the 2 POT and CUR integrations during heatwaves in (a) June and (b) August at 15:00 h UTC. Dashed lines: elevation (m, a.s.1.). Temperature differences above $\sim 0.75^{\circ} \mathrm{C}$ (or $<0.5^{\circ} \mathrm{C}$ ) are significant at $90 \%$ confidence level. Simulations: potential (POT) and current (CUR) vegetation distribution

feedbacks. $\delta F_{\text {SUR }}$ represents the contribution of vegetation change to atmospheric heating through the modification of the vegetation dependent partitioning between sensible and latent fluxes.

Fig. 4 shows the spatial patterns of $\delta F$ averaged over the 2 heatwave periods, as well as the contributions of $\delta F_{\mathrm{RAD}}, \delta F_{\mathrm{GRAD}}$ and $\delta F_{\mathrm{SUR}}$ to the mean change. In June, $\delta F$ is mainly negative with the most negative values in the 2 regions where the temperature anomaly is the highest (i.e. northwest and north-east of the Massif Central; compare Fig. 3a). Fig. 4c,e,g show that the largest contributor to $\delta F$ is $\delta F_{\text {SUR }}$. It accounts for $78 \%$ of $\delta F$ in mean (i.e. the relative contribution $\delta F_{\text {SUR }} / \delta F$ ), and results from changes in the Bowen ratio mainly because of change in the surface sensible heat flux. Differences in incident solar radiation between POT and CUR simulations in June (up to $100 \mathrm{~W} \mathrm{~m}^{-2}$ locally) also contribute to the change in $\delta F$ but only marginally $(<1 \%)$. In contrast, $\delta F_{\text {GRAD }}$ limits the change in $\delta F_{\text {SUR }}$, which is of opposite sign and accounts for $22 \%$ of $\delta F$. Interestingly,

Fig. 4. $(\mathrm{a}, \mathrm{b})$ Difference of $F(\delta F)$ between POT and CUR simulations for the June and August heatwaves. Contribution to $\delta F$ from $(\mathrm{c}, \mathrm{d})$ cloud cover change $\left(\delta F_{\mathrm{RAD}}\right),(\mathrm{e}, \mathrm{f})$ atmospheric feedback $\left(\delta F_{\mathrm{GRAD}}\right)$, and $(\mathrm{g}, \mathrm{h})$ change of partitioning between heating and evaporation $\left(\delta F_{\text {SUR }}\right)$. Columns: June (left) and August (right) heatwaves. Dashed lines: elevation (m, a.s.l.). $F=$ ratio between downward radiation to turbulent heat fluxes (see Eq. 5). See Fig. 3 for definitions 
although $\delta F_{\text {SUR }}$ is of opposite sign, its spatial pattern is the same as that of $\delta F_{\mathrm{GRAD}}$ and is correlated $(\mathrm{R}=$ 0.32) to a certain degree with the temperature difference over the June heatwave. This highlights the dominant role of the change in turbulent heat fluxes induced by the prescribed LCC.

During the August heatwave, $\delta F$ is positive in the region where temperature is lower in POT than in CUR (north-east/south-west oriented band and over the Massif Central; see Fig. 3b). This difference is mainly dominated by changes in $\delta F_{\text {SUR }}$ where trees have replaced agriculture, and by changes in $\delta F_{\text {GRAD }}$ where natural grassland has replaced agriculture (see Fig. 2). In both cases, it is the different partitioning of available energy between sensible and latent fluxes caused by the different nature of the vegetation that constrains those changes. We will see in the following that the response of vegetation transpiration to heat is mainly responsible for this partitioning, as a decrease (increase) in transpiration leads to a larger (smaller) conversion of solar radiation into sensible heat flux.

Transpiration represents $\sim 80 \%$ of total evapotranspiration during summer in both POT and CUR simulations. Transpiration change is thus a key driver of temperature change and is a relevant indicator of the role of land cover on the modulation of temperature. It strongly depends on the time of the day. Fig. 5 shows the diurnal evolution of transpiration of the 4 main PFTs for both simulations during the heatwaves in June and August, and during the month of July 2003. Transpiration of $\mathrm{NC}_{3}$ grass and evergreen needleleaf trees from the POT simulation are compared to that of $\mathrm{AC}_{3}$ crops and evergreen broadleaf trees from the CUR simulation. Broadleaf deciduous trees are also examined. Transpiration of the PFTs temperate broadleaf summergreen trees (TBS), $\mathrm{AC}_{3}$, evergreen and $\mathrm{NC}_{3}$ (Fig. 5b,c,d,e) are summed to compute the total transpiration (Fig. 5a). The contribution of the other PFTs is negligible $(<1 \%)$. At 15:00 $\mathrm{h}$ UTC, the mean transpiration in the CUR simulation is $0.75 \mathrm{~mm} \mathrm{~d}^{-1}$ larger than in the POT simulation during the June heatwave. Conversely, in August, the transpiration in the POT simulation exceeds that of the CUR simulation by $0.45 \mathrm{~mm} \mathrm{~d}^{-1}$. The transpiration in the CUR simulation decreases during summer from 4 to $2.4 \mathrm{~mm} \mathrm{~d}^{-1}$, because of the reduction of $\mathrm{AC}_{3}$ transpiration (Fig. 5c). In the POT simulation, on the other hand, transpiration remains largely unchanged in the morning, while a substantial reduction $\left(1 \mathrm{~mm} \mathrm{~d}^{-1}\right)$ appears in the afternoon from 13:00 to 18:00 UTC during the August heatwave. The change in forest transpiration is the main cause of the
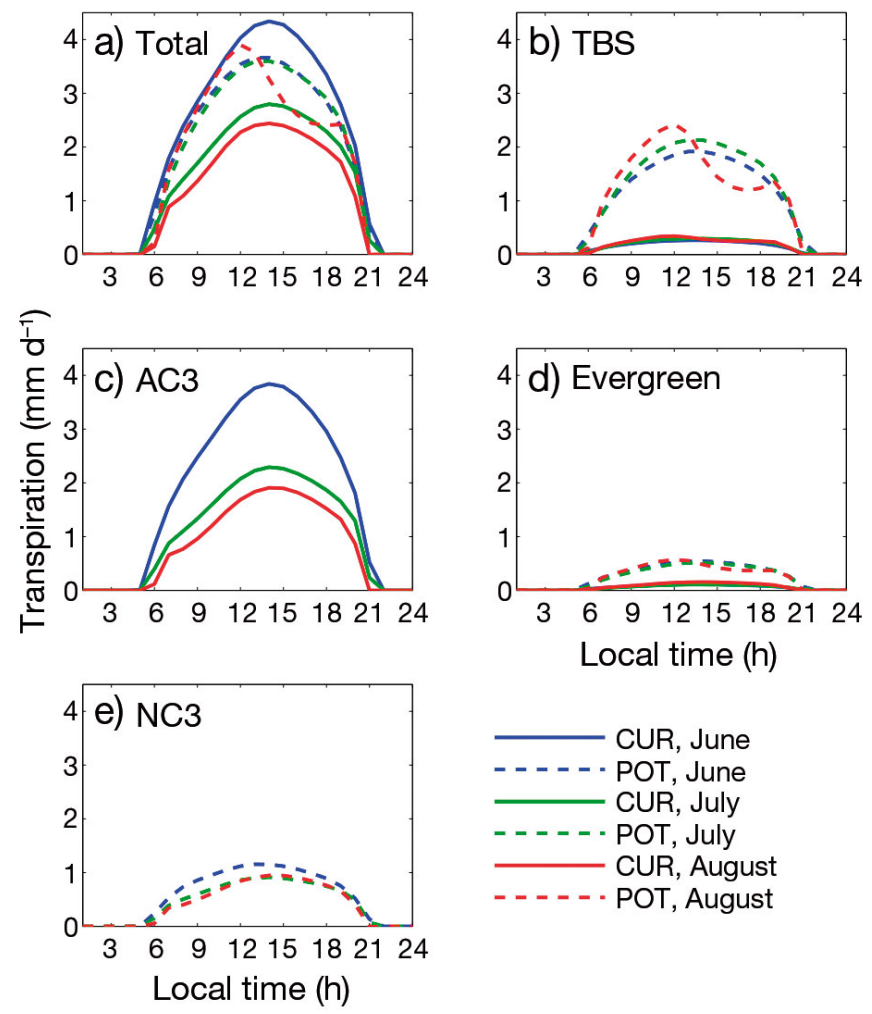

Fig. 5. Mean diurnal cycle of transpiration for the POT (dashed) and CUR (solid) simulations, for (a) the whole vegetation, (b) the temperate broadleaf summergreen trees (TBS), (c) agricultural $\mathrm{C}_{3}$ grass $\left(\mathrm{AC}_{3}\right)$, (d) the temperate evergreen trees, and (e) natural $\mathrm{C}_{3}$ grass $\left(\mathrm{NC}_{3}\right)$. June and August values are during the respective heatwaves

afternoon evaporation decrease in POT during the August heatwave (see Fig. 5b). This fall in evapotranspiration and its underlying mechanism will be further analyzed in Section 3.2. Concerning the $\mathrm{NC}_{3}$ and evergreen trees, their transpiration rate remains fairly constant during summer $\left(\sim 1\right.$ and $0.5 \mathrm{~mm} \mathrm{~d}^{-1}$, respectively).

For the $\mathrm{C}_{3}$ crops, which dominate in the CUR simulation, the transpiration decreases during summer with values in August 2 times smaller than in June (Fig. 5c). In fact, cropland switches from an energy limited evapotranspiration regime (early summer) to a water limited regime (late summer). In POT, the $\mathrm{C}_{3}$ grass transpiration is smaller throughout the summer (Fig. 5e), mainly due to the much smaller LAI than that of crops. As a consequence, grasslands mostly remain in an energy limited evapotranspiration regime during the summer months, and an evapotranspiration decrease for $\mathrm{C}_{3}$ grass is thus less pronounced in contrast to $\mathrm{C}_{3}$ crops.

This difference in response over grassland and forested areas has already been highlighted by Teul- 
ing et al. (2010); grass and crops can lose more water through evapotranspiration than trees during heatwaves as long as moisture is not a limiting factor. In the long term, deep-rooted trees benefit from a longer access to soil water, which mitigates the drought effect, whereas the herbaceous vegetation collapses. Consequently the differences in water use (and thereby resilience to heat stress for trees) result in a sign switch at the beginning of July that can be observed for several parameters, such as temperature.

In order to analyse this feature in more depth, Fig. 6 shows the time series (2002 to 2003) for the daily average difference between POT and CUR simulations for surface temperature and evapotranspiration (very similar curves are obtained for minimum temperature or temperature at 15:00 h UTC). At the beginning of the years, POT is warmer than CUR (essentially in response to smaller albedo values in POT), but after a few months the situation is the opposite (in response to dominant changes in turbulent fluxes). The timing of the switch from warmer to colder surface temperature takes place 2 wk earlier in 2003 than in 2002. The timing of the switch from smaller to larger evapotranspiration rates is shifted from spring to early summer in 2003 compared to
2002. Surface temperature and evapotranspiration differences show a larger variability, amplitude and anti-correlation in 2003 than in 2002 ( $\mathrm{r}=-0.87$ and -0.56 , respectively). This implies that during 2003 the sensitivity of surface heat fluxes and temperature to LCC increased compared to radiative (i.e. albedo and cloud cover) and large scale processes. A short analysis of the reflected solar radiation has shown that the most important effect of albedo on climate occurs over the May-September period, where POT stores more radiative energy than CUR $\left(10 \mathrm{~W} \mathrm{~m}^{-2}\right)$ due to a lower albedo (not shown). Nevertheless this additional energy does not prevent POT from maintaining a better land surface cooling efficiency from July to September, and cannot explain the temperature sign switch.

\subsection{Analysis of phenological behavior}

While Fig. 6 shows that the temperature difference at high and low frequency variability is driven by the evapotranspiration, it also raises a number of issues:

1. Temperature and evapotranspiration differences between POT and CUR have a larger variability and amplitude in 2003 compared to 2002.

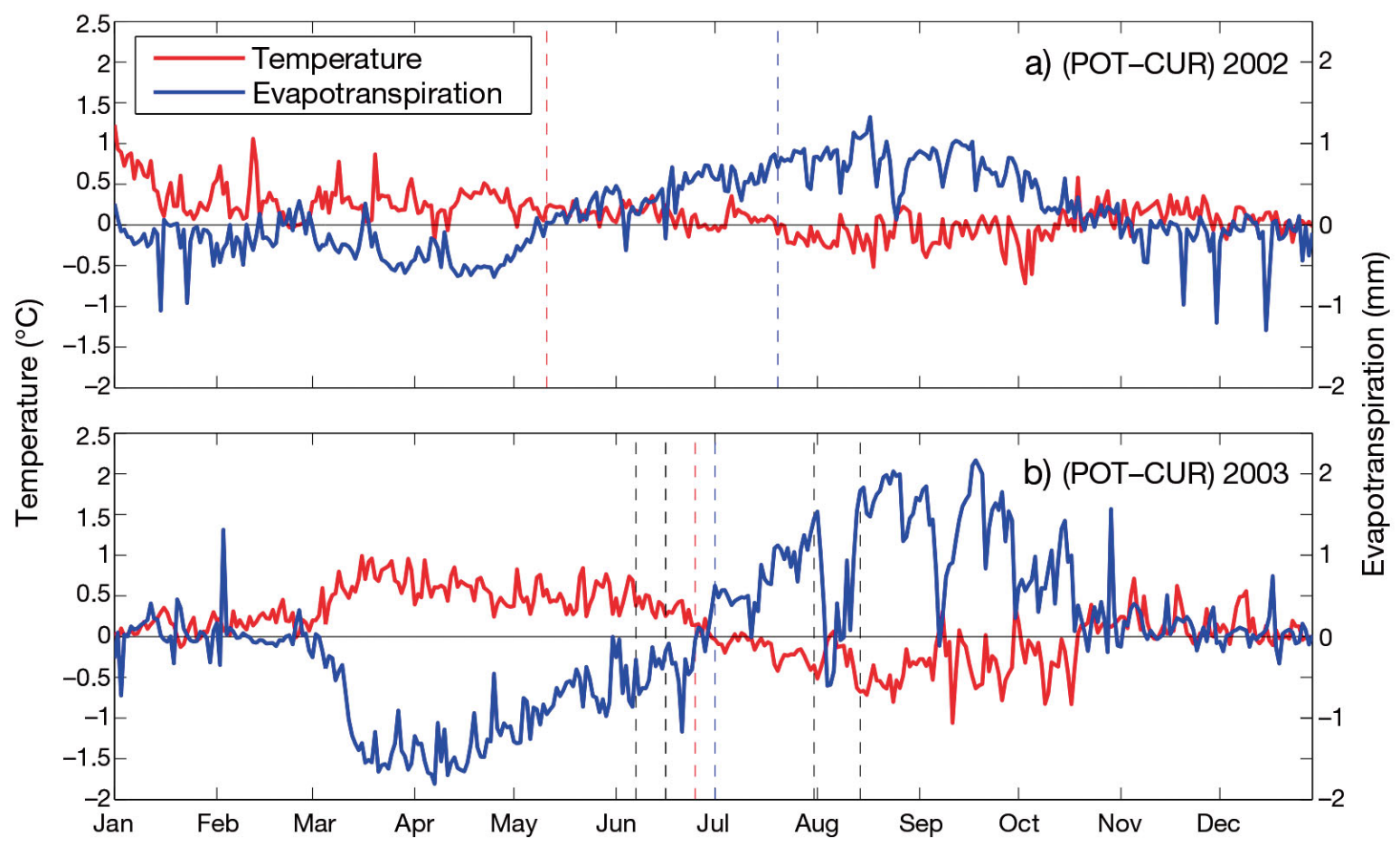

Fig. 6. Difference between the POT and CUR simulations for the evapotranspiration (blue) and surface temperature (red) at 15:00 h UTC for (a) 2002 and (b) 2003. Dashed lines - black: limit of June and August heatwaves; blue (red): sign switch in temperature (evapotranspiration) difference. See Fig. 3 for definitions 
2. The sign switch in evapotranspiration difference for 2002 occurs in May, while it occurs in July (2 mo later) in 2003.

3. In the afternoon during the August heatwave, there is an important decrease in forest transpiration for the POT simulation, resulting in a reduced temperature difference between POT and CUR.

In order to understand these 3 points we look further into the dynamics of vegetation phenology. The LAI and gross primary production (GPP) are diagnostics of the vegetation condition at a given time. LAI is a partial indicator of the ability of the vegetation to evaporate water from the soil root zone. GPP is an indicator of the instantaneous activity of the plant, positively correlated with stomata opening and evapotranspiration. Fig. 7 displays the temperature and LAI differences between the POT and CUR simulations for 2002 and 2003. The similarities between the two simulations arise because the LAI difference is strongly correlated with evapotranspiration (compare Fig. 6), since larger leaf surface increases evapotranspiration efficiency and vice versa. The amplitude of the LAI difference is larger in 2003 than in 2002, as it ranges from -1.6 to 2 and -0.9 to 1.1 , respectively. The larger temperature differences in 2003 are thus driven by larger LAI difference.
Fig. 8 displays the LAI and GPP in 2002 and 2003 for the 2 simulations. The 2003 vegetation in the CUR simulation shows a more intense LAI development that starts in early March, 1.5 mo before POT. Such a phenomenon has been observed in satellite imagery. For instance, based on a data set covering the period 2000-2007, Szczypta (2012) and Lafont et al. (2012) reported a long cycle of observed LAI in 2002. For 2003, they reported an early LAI increase and a fast decrease in summer. In an analysis of normalized difference vegetation index (NDVI) time series, Zaitchik et al. (2006) also pointed out the early leaf onset and the summer fall of leaves in 2003. The POT simulation has a later and less pronounced leaf onset than CUR in the middle of April (with 2.9 and $3.8 \mathrm{~m}^{2} \mathrm{~m}^{-2}$ for maximum LAI, respectively). Being dominated by the agricultural PFTs, the CUR phenological cycle, from the point of view of the LAI, is shorter and more sharply peaked. The POT seasonal variations are less peaked because vegetation is composed of a mix of forest and herbaceous vegetation that have different phenological cycles. The evolution of the LAI of herbaceous PFTs is comparable to that of agricultural PFTs in ORCHIDEE, although with an amplitude 4 times smaller, whereas the TBS PFT has a longer growing season extending from May to October,

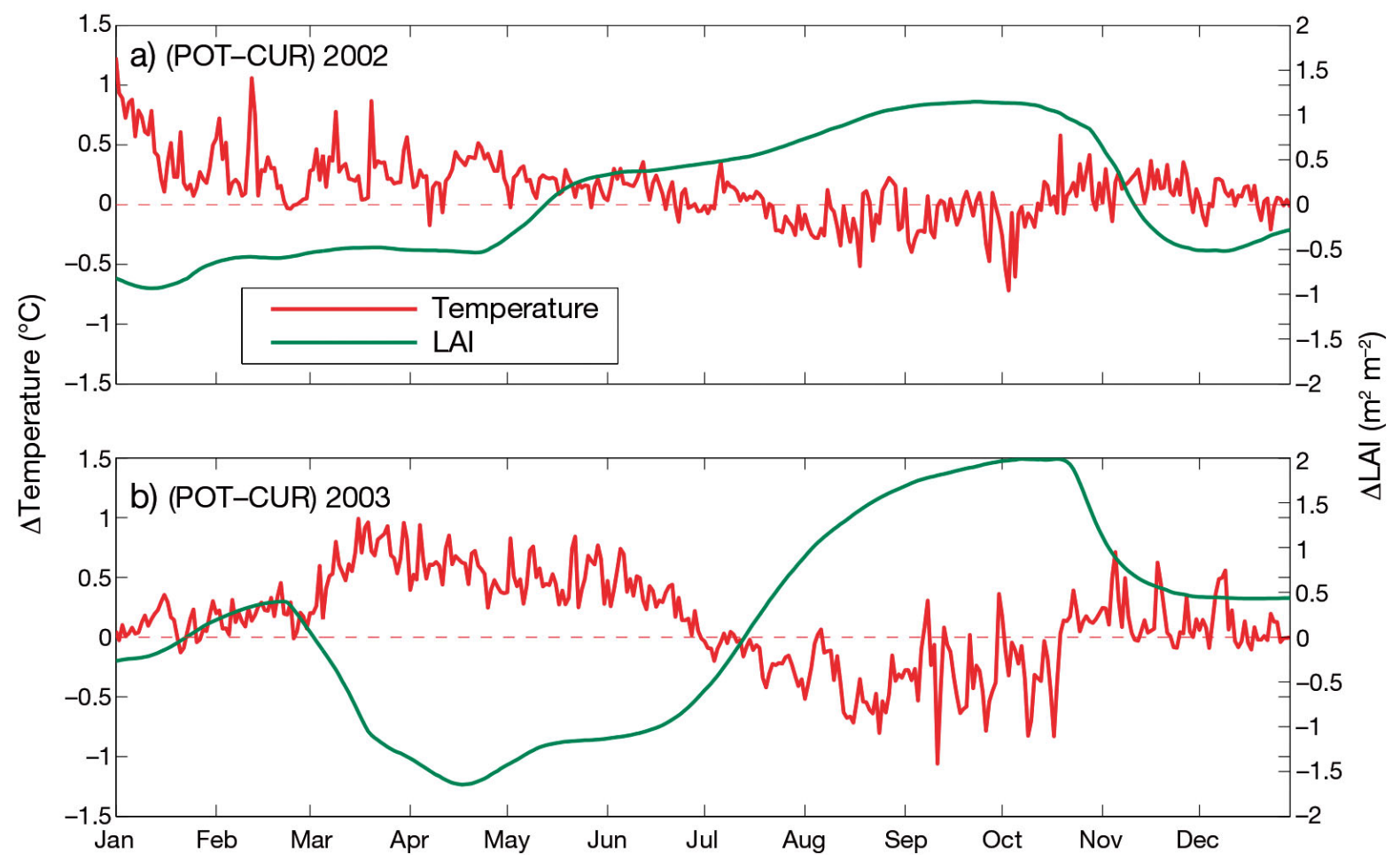

Fig. 7. Temperature difference at 15:00 h UTC (red) and leaf area index (LAI) difference (green) between the potential (POT) and current (CUR) vegetation distribution simulations for (a) 2002 and (b) 2003 


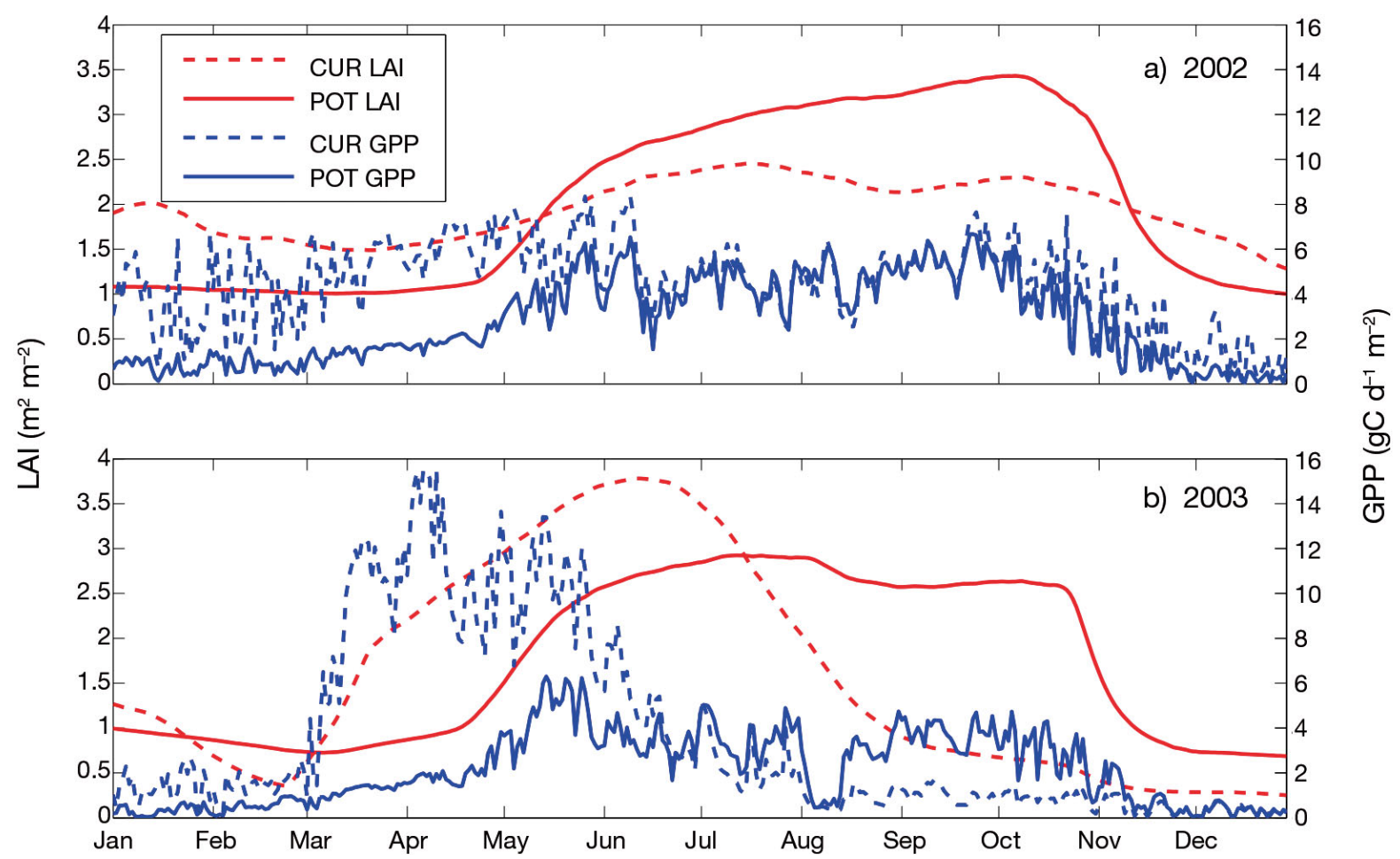

Fig. 8. Time series of the (a) 2002 and (b) 2003 gross primary production (GPP; blue) and LAI (red) for POT (solid) and CUR (dashed), averaged over the simulation domain. See Fig. 7 for definitions

where it reaches its maximum that remains lower than the agricultural PFTs maximum. In ORCHIDEE, $\mathrm{C}_{3}$ herbaceous vegetation cannot exceed an upper bound equal to $2.5 \mathrm{~m}^{2} \mathrm{~m}^{-2}$, whereas this value for $\mathrm{C}_{3}$ crops is equal to $5 \mathrm{~m}^{2} \mathrm{~m}^{-2}$. The LAI difference between the $\mathrm{C}_{3}$ plants is explained by this upper bound.

Three atmospheric parameters can also influence the LAI growth in ORCHIDEE, namely, temperature, rainfall and solar radiation. Cumulated rainfall difference between 2002 and 2003 is not large during the leaf onset from March to June for both simulations ( $<25 \mathrm{~mm}$; not shown); however, solar downward radiation and temperature are respectively $31 \mathrm{~W} \mathrm{~m}^{-2}$ $\left(29 \mathrm{~W} \mathrm{~m}^{-2}\right)$ and $1.6^{\circ} \mathrm{C}\left(1.26^{\circ} \mathrm{C}\right)$ higher during 2003 compared with 2002 for POT (CUR). These favorable spring weather conditions occur during the growth period for CUR agriculture PFTs, while it is too early for POT to benefit. For this reason, the LAI difference between the simulations increased in 2003 compared to 2002. These phenology changes induced by the spring weather conditions are the primary cause of point 2 above: the evapotranspiration sign switch occurring in July instead of May for the year 2003.

In spring 2002, in the absence of favorable weather conditions, CUR vegetation shows lower LAI values than in spring 2003. POT vegetation has a leaf onset later than CUR, and is hence less affected by meteor- ology in spring (Fig. 8a). During the last part of the 2002 summer, POT has an even more productive vegetation with an increased GPP and LAI compared to 2003, probably caused by the absence of a heatwave and drought.

The GPP values are consistent with the LAI. In 2003, CUR has higher values than POT during the growth phase (3 times larger, with 11.1 and $3.3 \mathrm{gC}$ $\mathrm{d}^{-1} \mathrm{~m}^{-2}$, respectively), but this phase is 4 mo shorter for CUR (see Fig. 8b). Concerning the POT simulation, GPP falls abruptly from 4 to $0.5 \mathrm{gC} \mathrm{d}^{-1} \mathrm{~m}^{-2}$ during the August heatwave, which induces a non significant LAI reduction of $0.3 \mathrm{~m}^{2} \mathrm{~m}^{-2}$ a few days after the GPP decay. Fig. 5 shows that the transpiration of trees in POT is similar in June, July, and August until 12:00 $\mathrm{h}$ UTC. It is consistent with the fact that LAI remains unchanged during summer. During the August heatwave, POT transpiration decreases abruptly after 12:00 $\mathrm{h}$, continuing this decline until $\sim 18: 00 \mathrm{~h}$ UTC, suggesting that past noon, the temperature becomes so high that it causes the closing of stomata and a drastic reduction of evapotranspiration and carbon assimilation.

Two environmental factors can inhibit transpiration by stomatal conductance decrease (see Eq. 3): low soil moisture and very high temperature, which reduce the carbon assimilation. Usually temperatures 
in Europe are not high enough to reach the critical threshold value for any PFT; However, the August heatwave coincided with the normal peak of summer temperatures (Luterbacher et al. 2004) and surface temperature reached $41^{\circ} \mathrm{C}$ in south-western France, which is $3^{\circ} \mathrm{C}$ above the threshold value for TBS trees $\left(38^{\circ} \mathrm{C}\right)$. Consequently the low stomatal conductance limits the latent heat flux in most of the domain in POT. This is shown in Fig. 9, which displays the soil moisture $\left(\varepsilon_{\text {water }}\right)$ and temperature ( $\left.\varepsilon_{\text {temp }}\right)$ factors for the dominant PFT over the domain at 15:00 h UTC. The quantity $\varepsilon_{\text {water }}$ does not vary significantly over the day.

In the POT simulation, the herbaceous PFT has low evaporative capacity and is already severely affected by soil moisture stress and senescence (Fig. 9a). Concerning the forests, the relationship between the latent heat flux and TBS $\varepsilon_{\text {temp }}$ appears clearly from the high correlation $(\mathrm{r}=0.88)$ between the patterns in Fig. 9c,e. Broadleaf summergreen trees still transpire water at a medium elevation $(>500 \mathrm{~m}$ ) and north of the domain along the domain boundary. This limitation by temperature explains the afternoon transpiration reduction in POT during the August heatwave (see Fig. 5b). The correlation between the latent heat flux and $\varepsilon_{\text {temp }}$ is lower in CUR $(r=0.60)$ because there is little TBS and a majority of croplands $(90 \%)$, which have a threshold for heat stress factor of $48^{\circ} \mathrm{C}$, which is higher than the simulated air temperature during the heatwaves. The lack of transpiration in CUR is related to early death of agricultural PFTs (Stéfanon et al. 2012b) and to soil moisture stress, as attested by the value of $\varepsilon_{\text {water }}$ for crops (Fig. 9b) whereas in POT it is related to heat stress. Both simulations undergo assimilation limitation that causes stomata closure and a decrease in transpiration, but this closure is induced by different environmental factors: high temperature for POT and low soil moisture for CUR.

\subsection{Comparison with previous studies}

Several studies have investigated LCC in the Mediterranean region, but have had conflicting conclusions. As mentioned in the introduction, Anav et al. (2010a) and Zampieri \& Lionello (2011) found that the replacement of trees by crops caused increased evapotranspiration and decreased surface temperature during summers 1981-2000 and 1992-2001 respectively. This is particularly true for heatwave summers. Our results are thus consistent with theirs. However they do not observe a change of sign in the evapotranspiration and temperature difference during summer. In the CUR simulation, interactions between atmosphere and vegetation phenology play a leading role in the sign reversal. The spring meteorological conditions favor the early and fast development of agricultural vegetation, reducing the soil moisture until it reaches a

Fig. 9. Photosynthesis limitation (see Eq. 3) by (a,b) soil moisture, (c,d) temperature and (e,f) latent heat flux for POT (left column) and CUR (right) for the dominant plant functional types (PFTs) over the domain (broadleaf summergreen trees and crops for POT and CUR, respectively). Values: close to $1=$ total absence of stress for plant transpiration, close to $0=$ high stress and no transpiration. Results are averaged at 15:00 h UTC over the heatwave period in August 2003. Dashed lines: elevation (m, a.s.l.). See Fig. 7 for definitions 
critical low value below which crop evaporation is strongly limited. In 2002, the sign of the surface temperature and evapotranspiration differences also switches during summer, but the differences are lower than in 2003. This supports previous findings (Anav et al. 2010a) showing that LCC impact on climate is amplified during heatwaves.

In the afforestation simulation for the 1987-1992 period of Heck et al. (2001), evidence of such a sign switch is shown with a cooling during the early summer and a warming in August. Because of larger LAI and deeper roots, trees transpire larger amounts of water than crops from April to mid-July. However in August, the critical soil moisture stress plays a role in inhibiting any evapotranspiration and enhancing sensible heat flux, thus amplifying the temperature. In our study, we reach the opposite conclusions during the 2003 summer heatwaves because the LAI of agricultural vegetation is larger than that of forest vegetation from April to mid-July and becomes smaller in August.

\section{CONCLUSION}

This study analyses the impact on the periods of extreme hot temperatures (summer 2003) of an afforestation scenario compared with a scenario dominated by agricultural vegetation (i.e. potential and current vegetation). Two high resolution simulations with the 2 different vegetation distributions are performed over the center of France. We found that reforesting and replacing part of the agriculture with natural prairies play a role in amplifying the temperature anomaly from March to June 2003, while it dampens the temperature anomaly from July to October 2003 - with however a limited dampening during the extreme 2 wk period in August. For the 2 heatwaves, the extreme values of temperature anomaly are modified by $5 \%$ and up to $37 \%\left(3^{\circ} \mathrm{C}\right)$ in specific gridpoints.

During spring 2003, agricultural plants have a greater photosynthetic activity and transpiration than trees because of a faster and stronger growth. The enhanced latent heat flux reduces surface warming during this period until the first heatwave. In July the vegetation starts to be limited by soil moisture, and agricultural plants are the most affected because of their shallow roots; trees can still transpire, and thus have a greater cooling effect than crops.

This cooling capacity is limited during the August heatwave, when very high temperatures inhibit carbon assimilation in trees during the warmest hours of the day. With no photosynthetic activity, the stomata close and stomatal resistance increases to its maximum. Crop transpiration during this period is reduced by the low soil moisture and the decreasing LAI induced by senescence. High elevation areas remain the only location where no limitations take place, due to the lower temperatures.

The favorable weather conditions in spring 2003 amplify the CUR phenological cycle, and thus induce larger LAI differences with respect to 2002. Larger LAI differences mean higher temperature difference between the integrations for 2003, due to the changes in transpiration. Consequently the particular meteorological conditions of 2003 exacerbate the difference between potential and current simulations compared to the more standard 2002 conditions in terms of LAI (Szczypta 2012) and temperature.

Limitation of assimilation by high temperature and induced transpiration inhibition have already been found in field experiments (Wang et al. 2008, Bauweraerts et al. 2013), but to the best of our knowledge never by modeling. Considering that by the end of the 21st century, summers similar to 2003 could be more frequent (Beniston 2004), climate model users should be cautious about this feedback mechanism when analysing projections of future summer climate and land-surface interactions.

Our experimental set-up, though academic, demonstrates how choices of land-cover distribution (e.g. trees versus crop extent) and/or species (e.g. tree type) may dampen or amplify extreme temperature events. Impacts of land distribution on local/ regional climate through biophysical feedbacks are indeed almost immediate, while mitigation through changes in greenhouse gases (GHG) is a longer-term process that may be preceded by periods with adverse effects of GHG-induced climate change. Our study also shows that land-surface interactions during summer heatwaves are extremely complex and still require research for a consensus to be reached on their effect on regional climate. Beyond the direct effect of land cover on heatwaves, other non-climatic benefits of forests versus agriculture and vice-versa should be considered. Nevertheless our study constitutes one aspect that can be considered in scenarios of land management.

Acknowledgements. This work has been supported by the Humboldt and MORCE-MED projects funded by the GIS (Groupement d'Intérêt Scientifique) 'Climat, Environnement et Société'. This work has also been carried out in the framework of the LABEX BASC (Biodiversity, Agrosystems, Society and Climate), referred to as ANR-11-LABX-0034. 
This work also contributes to the HyMeX program (HYdrological cycle in The Mediterranean Experiment, Drobinski et al. 2014) through INSU-MISTRALS support and the GEWEX program of WCRP. We are also grateful to the anonymous reviewers for their valuable and constructive comments on the manuscript. The authors are also grateful to Robert Jones for proofreading the article.

\section{LITERATURE CITED}

Anav A, Ruti PM, Artale V, Valentini R (2010a) Modelling the effects of land-cover changes on surface climate in the Mediterranean region. Clim Res 41:91-104

Bakkenes M, Alkemade J, Ihle F, Leemans R, Latour J (2002) Assessing effects of forecasted climate change on the diversity and distribution of European higher plants for 2050. Glob Change Biol 8:390-407

Ball JT (1987) A model predicting stomatal conductance and its contribution to the control of photosynthesis under different environmental conditions. Prog Photosynthesis Res Proc Int Congress 7th, Providence 10-15 Aug 1986, Vol. 4, Kluwer, Boston, MA, p 221-224

Ballester J, Giorgi F, Rodó X (2010) Changes in European temperature extremes can be predicted from changes in PDF central statistics. Clim Change 98:277-284

Bauweraerts I, Wertin TM, Ameye M, McGuire MA, Teskey RO, Steppe K (2013) The effect of heat waves, elevated [CO2] and low soil water availability on northern red oak (Quercus rubra L.) seedlings. Glob Chang Biol 19: 517-528

Beniston M (2004) The 2003 heat wave in Europe: a shape of things to come? An analysis based on Swiss climatological data and model simulations. Geophys Res Lett 31: L02202, doi:10.1029/2003GL018857

Boisier JP, de Noblet-Ducoudré N, Pitman AT, Cruz F and others (2012) Attributing the impacts of land-cover changes in temperate regions on surface temperature and heat fluxes to specific causes: results from the first LUCID set of simulations. J Geophys Res 117:D12116, doi: 10.1029/2011JD017106

> Bonan GB (2008) Forests and climate change: forcings, feedbacks, and the climate benefits of forests. Science 320 : 1444-1449

> Cassou C, Terray L, Phillips AS (2005) Tropical Atlantic influence on European heat waves. J Clim 18:2805-2811

> Chalita S, Le Treut H (1994) The albedo of temperate and boreal forest and the Northern Hemisphere climate: a sensitivity experiment using the LMD GCM. Clim Dyn 10:231-240

> Collatz GJ, Ball JT, Grivet C, Berry JA (1991) Physiological and environmental regulation of stomatal conductance, photosynthesis and transpiration: a model that includes a laminar boundary layer. Agric For Meteorol 54:107-136

Cox PM, Betts R, Collins M, Harris P, Huntingford C, Jones C (2004) Amazonian forest dieback under climatecarbon cycle projections for the 21st century. Theor Appl Climatol 78:137-156

Davin EL, de Noblet-Ducoudré N (2010) Climatic impact of global-scale deforestation: radiative versus nonradiative processes. J Clim 23:97-112

de Noblet-Ducoudré N, Boisier JP, Pitman A, Bonan G and others (2012) Determining robust impacts of land-useinduced land cover changes on surface climate over North America and Eurasia: results from the first set of
LUCID experiments. J Clim 25:3261-3281

Dee DP, Uppala SM, Simmons AJ, Berrisford P and others (2011) The ERA-Interim reanalysis: configuration and performance of the data assimilation system. QJR Meteorol Soc 137:553-597

Della-Marta PM, Haylock MR, Luterbacher J, Wanner H (2007) Doubled length of Western European summer heat waves since 1880. J Geophys Res 112:D15103, doi: 10.1029/2007JD008510

> Drobinski P, Anav A, Lebeaupin Brossier C, Samson G and others (2012) Model of the Regional Coupled Earth system (MORCE): application to process and climate studies in vulnerable regions. Environ Model Softw 35:1-18

Drobinski P, Ducrocq V, Alpert P, Anagnostou E and others (2014) HyMeX, a 10-year multidisciplinary program on the Mediterranean water cycle. Bull Am Meteorol Soc, doi:10.1175/BAMS-D-12-00242.1

> Ducoudré N, Laval K, Perrier A (1993) SECHIBA, a new set of parameterizations of the hydrologic exchanges at the land-atmosphere interface within the LMD atmospheric general circulation model. J Clim 6:248-273

> Easterling DR, Meehl GA, Parmesan C, Changnon SA, Karl TR, Mearns LO (2000) Climate extremes: observations, modeling, and impacts. Science 289:2068-2074

Farquhar GD, Caemmerer S, Berry JA (1980) A biochemical model of photosynthetic $\mathrm{CO}_{2}$ assimilation in leaves of $\mathrm{C}_{3}$ species. Planta 149:78-90

> Feudale L, Shukla J (2010) Influence of sea surface temperature on the European heat wave of 2003 summer. I. An observational study. Clim Dyn 36:1691-1703

Findell KL, Shevliakova E, Milly PCD, Stouffer RJ (2007) Modeled impact of anthropogenic land cover change on climate. J Clim 20:3621-3634

Fischer EM, Seneviratne SI, Vidale PL, Lüthi D, Schär C (2007) Soil moisture-atmosphere interactions during the 2003 European summer heat wave. J Clim 20: 5081-5099

Forster P, Ramaswamy V, Artaxo P, Berntsen T and others (2007) Changes in atmospheric constituents and in radiative forcing. In: Solomon S, Qin D, Manning M, Chen Z and others (eds) Climate Change 2007: the physical science basis. Contribution of Working Group I to the Fourth Assessment Report of the Intergovernmental Panel on Climate Change. Cambridge University Press, Cambridge

Gaertner MA, Christensen OB, Prego JA, Polcher J, Gallardo C, Castro M (2001) The impact of deforestation on the hydrological cycle in the western Mediterranean: an ensemble study with two regional climate models. Clim Dyn 17:857-873

Gálos B, Mátyás C, Jacob D (2011) Regional characteristics of climate change altering effects of afforestation. Environ Res Lett 6:044010, doi:10.1088/1748-9326/6/4/044010

Heck P, Lüthi D, Wernli H, Schär C (2001) Climate impacts of European-scale anthropogenic vegetation changes: a sensitivity study using a regional climate model. J Geophys Res 106:7817-7835

> Jackson RB, Randerson JT, Canadell JG, Anderson RG and others (2008) Protecting climate with forests. Environ Res Lett 3:044006, doi:10.1088/1748-9326/3/4/044006

> Klein Tank AMG, Konnen GP, Selten FM (2005) Signals of anthropogenic influence on European warming as seen in the trend patterns of daily temperature variance. Int $\mathrm{J}$ Climatol 25:1-16

Krinner G, Viovy N, de Noblet-Ducoudré N, Ogeé J and 
others (2005) A dynamic global vegetation model for studies of the coupled atmosphere-biosphere system. Global Biogeochem Cycles 19:GB1015, doi:10.1029/2003 GB002199

Lafont S, Zhao Y, Calvet J, Peylin P, Ciais P, Maignan F, Weiss M (2012) Modelling LAI, surface water and carbon fluxes at high-resolution over France: comparison of ISBA-A-gs and ORCHIDEE. Biogeosciences 9:439-456

Lean J, Rowntree PR (1997) Understanding the sensitivity of a GCM simulation of Amazonian deforestation to the specification of vegetation and soil characteristics. J Clim 10:1216-1235

Loveland TR, Reed BC, Brown JF, Ohlen DO, Zhu Z, Yang L, Merchant JW (2000) Development of a global land cover characteristics database and IGBP DISCover from $1 \mathrm{~km}$ AVHRR data. Int J Remote Sens 21:1303-1330

> Luterbacher J, Dietrich D, Xoplaki E, Grosjean M, Wanner $H$ (2004) European seasonal and annual temperature variability, trends, and extremes since 1500. Science 303: 1499-1503

Meissner KJ, Weaver AJ, Matthews HD, Cox PM (2003) The role of land surface dynamics in glacial inception: a study with the UVic Earth System Model. Clim Dyn 21:515-537

Pielke RA, Pitman A, Niyogi D, Mahmood R and others (2011) Land use/land cover changes and climate: modeling analysis and observational evidence. WIREs Clim Chang 2:828-850

Pitman AJ, de Noblet-Ducoudré N, Cruz FT, Davin EL and others (2009) Uncertainties in climate responses to past land cover change: first results from the LUCID intercomparison study. Geophys Res Lett 36:L14814, doi:10. 1029/2009GL039076

Schär C, Vidale PL, Lüthi D, Frei C, Haberli C, Liniger MA, Appenzeller C (2004) The role of increasing temperature variability in European summer heatwaves. Nature 427: 332-336

Skamarock WC, Klemp JB, Dudhia J, Gill DO and others (2008) A description of the Advanced Research WRF Version 3. NCAR Tech Rep TN-475, NCAR, Boulder, CO

Stéfanon M, D'Andrea F, Drobinski P (2012a) Heatwave classification over Europe and the Mediterranean region.

Editorial responsibility: Matthias Seaman,

Oldendorf/Luhe, Germany
Environ Res Lett 7:014023, doi:10.1088/1748-9326/7/1/ 014023

Stéfanon M, Drobinski P, D'Andrea F, Noblet-Ducoudré N (2012b) Effects of interactive vegetation phenology on the 2003 summer heat waves. J Geophys Res 117: D24103, doi:10.1029/2012JD018187

Szczypta C (2012) Space hydrology for the monitoring of Mediterranean droughts. PhD thesis, University of Toulouse

> Teuling AJ, Seneviratne SI, Stockli R, Reichstein M and others (2010) Contrasting response of European forest and grassland energy exchange to heatwaves. Nat Geosci 3: 722-727

Vautard R, Yiou P, D'Andrea F, de Noblet N and others (2007) Summertime European heat and drought waves induced by wintertime Mediterranean rainfall deficit. Geophys Res Lett 34:L07711, doi:10.1029/2006GL028001

Viovy N, de Noblet-Ducoudré N (1997) Coupling water and carbon cycle in the biosphere. Sci Geol Bull 50:109-121

> von Randow C, Manzi AO, Kruijt B, de Oliveira PJ and others (2004) Comparative measurements and seasonal variations in energy and carbon exchange over forest and pasture in South West Amazonia. Theor Appl Climatol 78: $5-26$

> Wang D, Heckathorn SA, Barua D, Joshi P, Hamilton EW, LaCroix JJ (2008) Effects of elevated $\mathrm{CO}_{2}$ on the tolerance of photosynthesis to acute heat stress in $\mathrm{C}_{3}, \mathrm{C}_{4}$, and CAM species. Am J Bot 95:165-176

Wramneby A, Smith B, Samuelsson P (2010) Hot spots of vegetation-climate feedbacks under future greenhouse forcing in Europe. J Geophys Res 115:D21119, doi:10. 1029/2010JD014307

Zaitchik BF, Macalady AK, Bonneau LR, Smith RB (2006) Europe's 2003 heat wave: a satellite view of impacts and land-atmosphere feedbacks. Int J Climatol 26:743-769

Zampieri M, Lionello P (2011) Anthropic land use causes summer cooling in Central Europe. Clim Res 46:255-268

> Zampieri M, D'Andrea F, Vautard R, Ciais P, de NobletDucoudré N, Yiou P (2009) Hot European summers and the role of soil moisture in the propagation of Mediterranean drought. J Clim 22:4747-4758

Submitted: August 22, 2013; Accepted: April 2, 2014

Proofs received from author(s): June 9, 2014 